\title{
PREVALENCE AND TRENDS OF METABOLIC SYNDROME IN CLIENTS OF HEALTH ADVICE CENTRES DURING THE YEARS 2003-2012
}

\author{
Tímea Ostrihoňová1, Kvetoslava Rimárová2, Janka Bérešová3, Silvia Kontrošová4, Erik Dorko², Jana Diabelková2 \\ ${ }^{1}$ General Hospital, Rimavská Sobota, Slovak Republic \\ 2Department of Public Health and Hygiene, Faculty of Medicine, Pavol Jozef Šafárik University in Košice, Košice, Slovak Republic \\ ${ }^{3}$ Regional Public Health Authority, Rimavská Sobota, Slovak Republic \\ ${ }^{4}$ Regional Public Health Authority, Banská Bystrica, Slovak Republic
}

\section{SUMMARY}

Objective: Metabolic syndrome is a combination of clinical risk factors for cardiovascular disease as well as for diabetes. Metabolic syndrome arises from insulin resistance accompanied with abnormal adipose deposition. The aim of our cross-sectional time trends study was to characterize the prevalence of metabolic syndrome and its five risk determinants among the clients of Health Advice Centres of Regional Public Health Authorities in Slovakia. The study was stratified by gender and age groups during the 10 year period from 2003-2012.

Methods: Prevalence data were estimated in adults and children ( $\geq 10$ years, $N=79,904)$ from the nationwide electronic database of Health Advice Centres of Regional Public Health Authorities in Slovak Republic "Test of healthy heart" from 2003 to 2012.

Results: The overall prevalence of metabolic syndrome was $30.2 \%$ in males and $26.6 \%$ in females, abdominal obesity was confirmed in $48.3 \%$ of males and $53.9 \%$ of females. Increased triglyceride level has higher prevalence among males $(33.3 \%)$ compared to females $(24.2 \%)$. Blood pressure (BP) values and fasting glucose values were significantly higher in males (58.2\%) than females (41.9\%). During the 10 year period from 2003 to 2012, we confirmed an increased trend in the age-adjusted prevalence of metabolic syndrome. Abdominal obesity and elevated triglycerides had also increased time trends prevalence in both sexes. The prevalence of people without risk determinants of metabolic syndrome had a time decreasing trend. A surprising finding is a decrease in the proportion of persons with suboptimal HDL-cholesterol. The proportion of people with elevated $\mathrm{BP}$ and glucose showed little change during the reporting period.

Conclusion: The increasing prevalence of metabolic syndrome, abdominal obesity, and elevated triglycerides highlights the urgency of addressing these health problems as a healthcare priority to reduce cardiovascular mortality in the Slovak Republic.

Key words: metabolic syndrome, Slovak Republic, abdominal obesity, hypertriglyceridemia, hyperglycemia, hypertension, HDL cholesterol

Address for correspondence: K. Rimárová, Department of Public Health and Hygiene, Faculty of Medicine, P. J. Šafárik University in Košice, Šrobárova 2, Košice, Slovak Republic. E-mail: kvetoslava.rimarova@upjs.sk

https://doi.org/10.21101/cejph.a4968

\section{INTRODUCTION}

Diabetes and cardiovascular diseases (CVD) are, together with cancer and chronic respiratory diseases, the world's biggest killers, causing an estimated 35 million deaths each year; $80 \%$ of these deaths occur in low- and middle-income countries (1). In 2009 among all OECD countries the highest ischaemic heart disease mortality rate was confirmed in the Slovak Republic for both males and females, followed by Estonia and Hungary. Since 1980, ischaemic heart disease mortality rates have declined in nearly all OECD countries. However, a small number of countries, including Hungary, the Czech Republic, Poland, and the Slovak Republic, have seen little or no decline since 1980 (2).

The clustering of metabolic risk factors with CVD and diabetes has been recognised for more than 80 years, but the modern concept of the metabolic syndrome (MetS) began when Reaven proposed a conceptual framework which linked apparently unrelated biological events into a single pathophysiological construct
(3). Subsequently, a number of different definitions have been developed for this purpose by the WHO (4), the National Cholesterol Education Program Adult Treatment Panel III (ATP III) (5), the European Group for the Study of Insulin Resistance (6), and the International Diabetes Federation (IDF) (7). Currently the Joint Interim Statement (consensus definition) highlights that there should be no obligatory component for MetS, rather all individual components should be considered important for risk prediction $(8,9)$. People with MetS have an increased risk for developing diabetes mellitus (10), cardiovascular disease (11) and have an increased mortality risk from CVD and other diagnoses $(12,13)$.

The rationale supporting the use of MetS includes the following: it provides a framework for research exploring a possible unifying pathophysiological basis for the observed cluster of risk factors; it quantifies chronic disease risk within populations and facilitates between-country comparisons; it can guide relative risk prediction and clinical management decisions; and it provides an easily comprehensible public health message and reminds health 
professionals of the need to assess also other related risk factors when one risk factor is detected (14).

The scientific aim of our paper was to examine trends in the prevalence of MetS and its five components among the clients of Health Advice Centres of the Regional Public Health Authorities in the Slovak Republic.

\section{MATERIAL AND METHODS}

The study design was created as a repeated cross-sectional survey and time trend evaluation research. Data collection was carried from 1 January 2003 to 31 January 2012 in Health Advice Centres of the 36 Regional Public Health Authorities in Slovakia. In total 202,836 clients were examined. They showed interest in health and wished to ascertain their individual risks of the most common chronic diseases. The purpose of our study was based on the following criteria of eligibility and we selected 79,904 respondents (26,239 males and 53,665 females with an average age of 44.59). The eligibility criteria included:

- The client's first visit of a Health Advice Centre;

- The client comprehensively examined (waist circumference, blood pressure, triglycerides, glucose, HDL-cholesterol);

- Minimum age was 10 years old (in accordance with "The International Diabetes Federation consensus definition of MetS in children and adolescents") (15).

All the data were obtained from the nationwide electronic database of Health Advice Centres of Regional Public Health Authorities "Test of healthy heart", in which data of all examined clients are stored. Blood test examination of the respondents was done with clients fasting in accordance with a uniform methodological guide for Health Advice Centres in Slovakia (16). Biochemical parameters were investigated in capillary blood using Reflotron type IV (manufacturer's declared accuracy is $\pm 0.5 \%$ ), which is in vitro diagnostic device designed for the quantitative determination of clinical chemistry parameters using test strips on the principle of reflectance photometry.

The presence of MetS and its risk determinants in children from 10 to 16 years of age was determined according to "the IDF consensus definition of the MetS in children and adolescents" (15). The presence of MetS and its risk determinants (central obesity, elevated triglycerides, reduced HDL-cholesterol, higher blood pressure, increased blood sugar) in adults and children 16 years old and older was determined according to the IDF definition from 2005 (17) - central obesity (defined as waist circumference $\geq 94 \mathrm{~cm}$ in males and $\geq 80 \mathrm{~cm}$ in females) plus any two of the following four factors (raised triglycerides $\geq 1.7$ $\mathrm{mmol} / \mathrm{l}$, reduced HDL-cholesterol $<1.03 \mathrm{mmol} / \mathrm{l}$ in males and in females $<1.29 \mathrm{mmol} / \mathrm{l}$, raised blood pressure (BP) systolic BP $\geq 130$ or diastolic $\mathrm{BP} \geq 85 \mathrm{mmHg}$, raised fasting plasma glucose $\geq 5.6 \mathrm{mmol} / \mathrm{l}$ ).

To examine the prevalence of MetS and its risk determinants over time we standardized prevalence estimates through the direct method of using the 2011 Slovak population as a standard.

Statistical analysis of the databases was performed with Microsoft Excel (version 2007). The prevalence of MetS and its risk determinants was expressed in absolute counts, and also as a relative indicator - the prevalence rate, calculated as the number of cases per 1,000 persons.

\section{RESULTS}

The number of respondents categorised by sex, age groups, and the year of examination is shown in Table 1. Frequency proportion by age groups confirmed higher number of clients in the age group $45-54$ years $(26.45 \%)$. Females also created a larger proportion (67.2\%) of all examined clients (Table 1, Fig. 1).

The overall prevalence of MetS in the total group was $30.2 \%$ in males (in children under 18 years $2.7 \%$ ) and $26.6 \%$ in females (in children under 18 years $2.8 \%$ ). Abdominal obesity (AO) was confirmed in $48.3 \%$ of males (in children under 18 years $7.6 \%$ ) and $53.9 \%$ of females (in children under 18 years $13.7 \%$ ). Elevated levels of triglycerides were present in $33.3 \%$ of males (in children under 18 years $11.8 \%$ ) and in $24.2 \%$ of females (in children under 18 years $8.7 \%$ ). Increased blood pressure (BP) values were found in $58.2 \%$ of males (in children under 18 years $18.7 \%$ ) and in $41.9 \%$ of females (in children under 18 years $8.9 \%$ ). Higher level of plasma glucose (after fasting) was present in $26.7 \%$ of males (in children under 18 years $10.2 \%$ ) and in $21.1 \%$ of females (in children under 18 years 9.1\%). HDL-cholesterol levels were reduced in $29.8 \%$ of males (in children under 18 years $29.8 \%$ ) and in $31.6 \%$ of females (in children under 18 years $31.9 \%$ ). The age was a significant factor connected with the prevalence increase of MetS, abdominal obesity, elevated triglycerides, glucose and BP. The prevalence of reduced HDL-cholesterol with increasing age did not change significantly (Table 2, Fig. 2).

The results of our study confirmed increasing age as main factor for gradual deteriorating of the mean values of waist circumference, triglycerides, glucose, systolic and diastolic BP (Table 3). Mean values of HDL-cholesterol were contrary because they very slightly increased with age. The average values of waist circumference in males exceeded the threshold established by the IDF definition of MetS in the 45-54 age group and in older age categories, and females in the 35-44 age group and in older age categories. The average values of triglycerides in males exceeded the threshold in the 35-44, 45-54 and 55-64 age groups, in females the threshold was not exceeded in either age group. The mean values of HDL levels were below the threshold values in each age group. Systolic BP in males exceeded the threshold in the 45-54 age group and in older age categories, in females in the 55-64 age group and in older age categories. Diastolic BP in males exceeded the threshold in the 45-54 age group, and in older age groups, in females threshold value was not exceeded in either age group. The glucose threshold was exceeded in males in the 55-64 age group and in the more than 65 years of age groups, and in females only in the more than 65 years of age group (Table 3 ).

Time trends analysis from 2003 to 2012 confirmed fact that the age-adjusted prevalence of MetS in both males and females has an increasing trend (Table 4). The prevalence of MetS in males (Fig. 3) exceeds the prevalence of MetS in females (males data varied from $247.09 / 1,000$ to $315.20 / 1,000$, females parameters varied from $234.37 / 1,000$ to $296.58 / 1,000$ ), with the exception of the years 2003 and 2005. Similarly, the age-adjusted prevalence of abdominal obesity (AO) and elevated triglyceride (TG) levels in both males and females has an increasing trend (Figures 4, 5). In females the prevalence of abdominal obesity throughout the period exceeds the prevalence of abdominal obesity in males (females 464.88 to 561.04/1,000, males 396.40 to $493.61 / 1,000$ ). The age-adjusted prevalence of elevated triglycerides, on the 

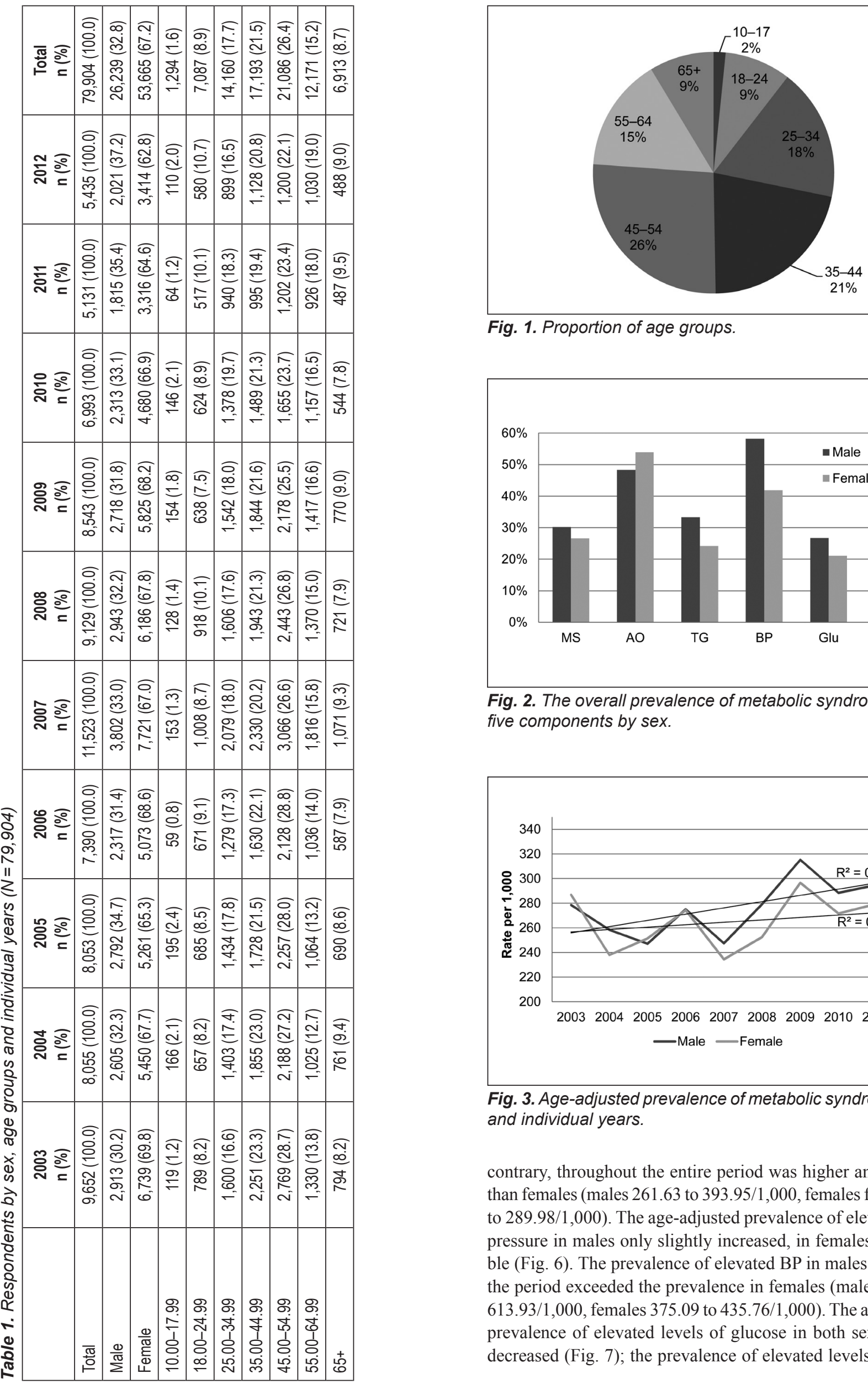

Fig. 1. Proportion of age groups.

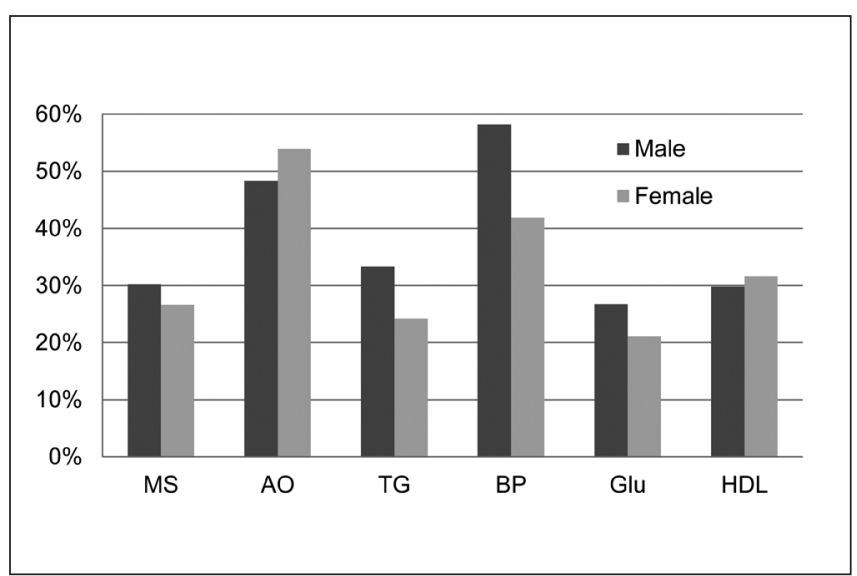

Fig. 2. The overall prevalence of metabolic syndrome and it's five components by sex.

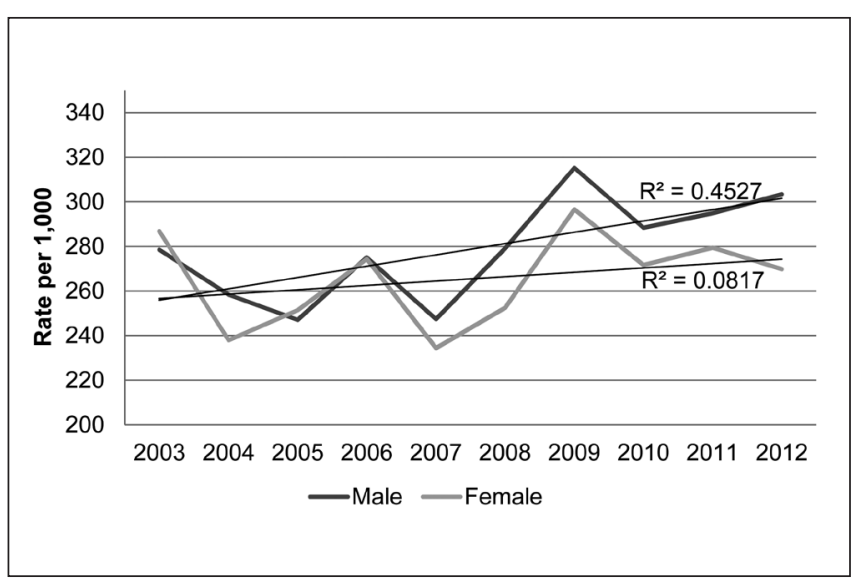

Fig. 3. Age-adjusted prevalence of metabolic syndrome by sex and individual years.

contrary, throughout the entire period was higher among males than females (males 261.63 to $393.95 / 1,000$, females from 178.51 to $289.98 / 1,000)$. The age-adjusted prevalence of elevated blood pressure in males only slightly increased, in females it was stable (Fig. 6). The prevalence of elevated BP in males throughout the period exceeded the prevalence in females (males 511.15 to $613.93 / 1,000$, females 375.09 to $435.76 / 1,000$ ). The age-adjusted prevalence of elevated levels of glucose in both sexes slightly decreased (Fig. 7); the prevalence of elevated levels of glucose 
Table 2. The overall prevalence of metabolic syndrome and it's five components by sex and age groups

\begin{tabular}{|c|c|c|c|c|c|c|c|}
\hline & & $\begin{array}{l}\text { MetS } \\
\mathrm{n}(\%)\end{array}$ & $\begin{array}{c}\mathrm{AO} \\
\mathrm{n}(\%)\end{array}$ & $\begin{array}{c}\text { TG } \\
\mathrm{n}(\%)\end{array}$ & $\begin{array}{c}\text { BP } \\
\text { n (\%) }\end{array}$ & $\begin{array}{c}\text { Glu } \\
\text { n (\%) }\end{array}$ & $\begin{array}{l}\mathrm{HDL} \\
\mathrm{n}(\%)\end{array}$ \\
\hline \multirow{8}{*}{ Male } & $10.00-17.99$ & $15(2.7)$ & $42(7.6)$ & 65 (11.8) & $103(18.7)$ & $56(10.2)$ & $164(29.8)$ \\
\hline & $18.00-24.99$ & $196(6.7)$ & $438(15.1)$ & $407(14.0)$ & $1,033(35.6)$ & 341 (11.7) & $940(32.4)$ \\
\hline & $25.00-34.99$ & 985 (19.2) & $1,844(36.0)$ & 1,518 (29.6) & 2,365 (46.1) & $714(13.9)$ & 1,594 (31.1) \\
\hline & 35.00-44.99 & $1,499(28.7)$ & $2,565(49.1)$ & $1,939(37.1)$ & $2,865(54.9)$ & $1,188(22.7)$ & $1,566(30.0)$ \\
\hline & $45.00-54.99$ & $2,335(38.9)$ & $3,548(59.1)$ & $2,490(41.4)$ & $3,975(66.2)$ & $2,022(33.7)$ & $1,753(29.2)$ \\
\hline & $55.00-64.99$ & $1,909(45.7)$ & $2,758(66.0)$ & 1,657 (39.7) & $3,147(75.3)$ & $1,701(40.7)$ & $1,158(27.7)$ \\
\hline & $65+$ & 991 (44.1) & $1,484(66.0)$ & $673(29.9)$ & 1,789 (79.6) & $979(43.5)$ & $655(29.1)$ \\
\hline & Total & $7,930(30.2)$ & $12,679(48.3)$ & $8,749(33.3)$ & $15,277(58.2)$ & $7,001(26.7)$ & $7,830(29.8)$ \\
\hline \multirow{8}{*}{ Female } & $10.00-17.99$ & $21(2.8)$ & $103(3.8)$ & $65(8.7)$ & $66(8.9)$ & $68(9.1)$ & $237(31.9)$ \\
\hline & $18.00-24.99$ & $166(4.0)$ & $741(17.7)$ & $450(10.8)$ & $524(12.5)$ & $323(7.7)$ & $1,401(33.5)$ \\
\hline & $25.00-34.99$ & 744 (8.2) & $2,560(28.3)$ & $1,084(12.0)$ & $1,694(18.8)$ & $910(10.1)$ & $2,698(29.9)$ \\
\hline & $35.00-44.99$ & 2,087 (17.4) & $5,335(44.6)$ & 2,282 (19.1) & $3,800(31.7)$ & $1,979(16.5)$ & $3,741(31.3)$ \\
\hline & $45.00-54.99$ & $4,983(33.0)$ & $9,955(66.0)$ & $4,387(29.1)$ & $7,711(51.1)$ & $3,686(24.4)$ & $4,619(30.6)$ \\
\hline & $55.00-64.99$ & $3,673(46.0)$ & $6,288(78.7)$ & $3,002(37.6)$ & $5,087(63.6)$ & $2,559(32.0)$ & $2,602(32.6)$ \\
\hline & $65+$ & $2,605(55.8)$ & $3,969(85.1)$ & $1,709(36.6)$ & $3,628(77.8)$ & $1,823(39.1)$ & $1,660(35.6)$ \\
\hline & Total & $14,279(26.6)$ & $28,951(53.9)$ & $12,979(24.2)$ & $22,510(41.9)$ & $11,348(21.1)$ & $16.958(31.6)$ \\
\hline
\end{tabular}

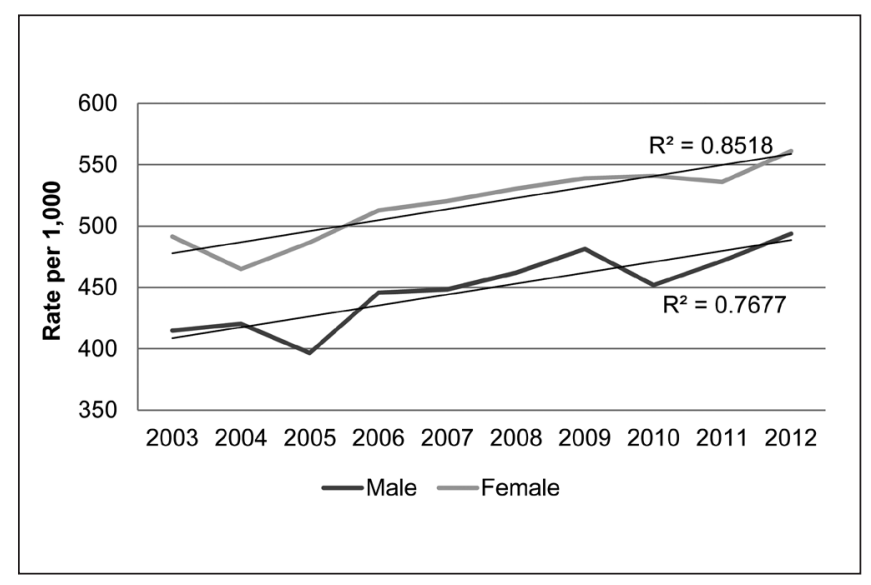

Fig. 4. Age-adjusted prevalence of abdominal obesity by sex and individual years.

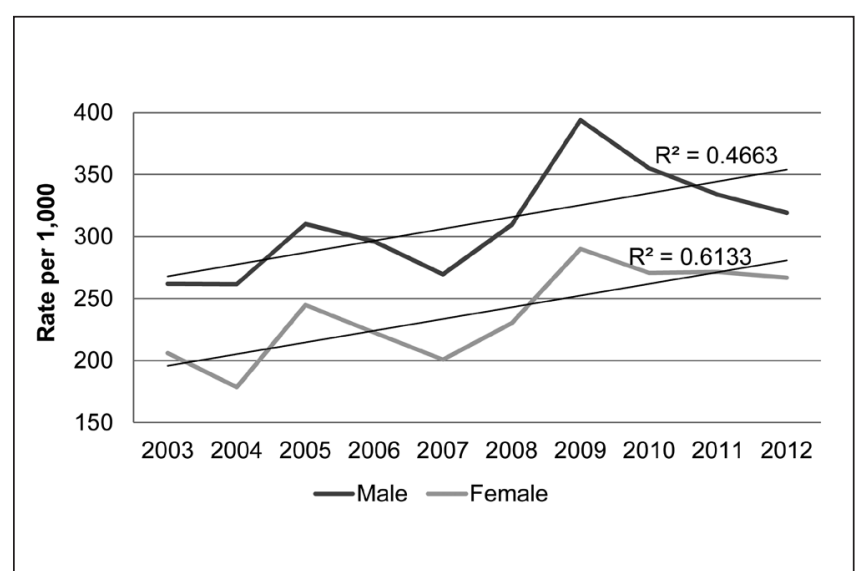

Fig. 5. Age-adjusted prevalence of elevated triglycerids by sex and individual years.

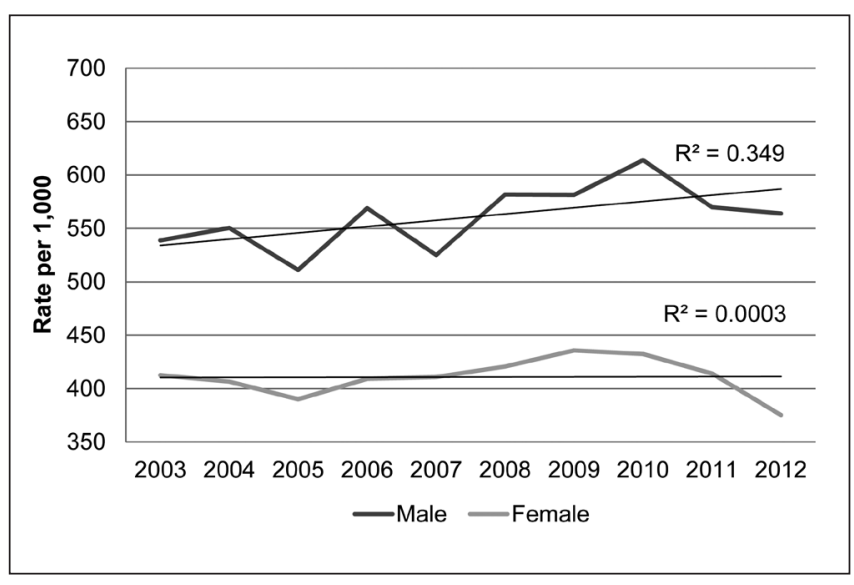

Fig. 6. Age-adjusted prevalence of high blood presure by sex and individual years.

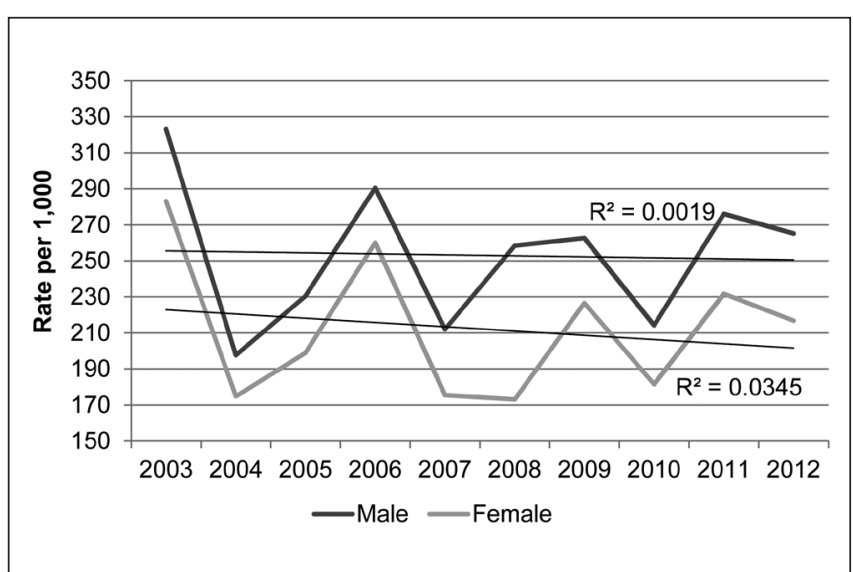

Fig. 7. Age-adjusted prevalence of elevated glucose by sex and individual years. 
Table 3. Mean values and standard deviation of five components of metabolic syndrome by sex and age groups

\begin{tabular}{|c|c|c|c|c|c|c|c|}
\hline & & $\begin{array}{l}\text { Glucose } \\
\mathrm{mmol} / \mathrm{l}\end{array}$ & $\begin{array}{c}\text { Triglycerides } \\
\mathrm{mmol} / / \mathrm{l}\end{array}$ & $\begin{array}{l}\text { HDL-cholesterol } \\
\mathrm{mmol} / \mathrm{l}\end{array}$ & $\begin{array}{c}\text { Systolic BP } \\
\text { mmHg }\end{array}$ & $\begin{array}{c}\text { Diastolic BP } \\
\mathrm{mmHg}\end{array}$ & $\begin{array}{l}\text { Waist circ. } \\
\mathrm{cm}\end{array}$ \\
\hline \multirow{8}{*}{ Male } & $10.00-17.99$ & $4.96 \pm 0.63$ & $1.09 \pm 0.49$ & $1.21 \pm 0.36$ & $116.80 \pm 14.37$ & $70.87 \pm 10.04$ & $77.72 \pm 10.12$ \\
\hline & $18.00-24.99$ & $4.94 \pm 0.77$ & $1.17 \pm 0.59$ & $1.21 \pm 0.40$ & $122.65 \pm 14.00$ & $75.52 \pm 9.48$ & $83.84 \pm 10.11$ \\
\hline & $25.00-34.99$ & $5.02 \pm 0.69$ & $1.51 \pm 0.90$ & $1.25 \pm 0.45$ & $125.62 \pm 14.09$ & $79.38 \pm 9.75$ & $90.50 \pm 10.41$ \\
\hline & $35.00-44.99$ & $5.22 \pm 0.86$ & $1.73 \pm 1.11$ & $1.27 \pm 0.46$ & $128.15 \pm 15.41$ & $82.43 \pm 10.57$ & $93.67 \pm 10.43$ \\
\hline & $45.00-54.99$ & $5.48 \pm 1.18$ & $1.80 \pm 1.09$ & $1.29 \pm 0.47$ & $133.21 \pm 17.42$ & $85.19 \pm 11.02$ & $95.99 \pm 10.43$ \\
\hline & $55.00-64.99$ & $5.72 \pm 1.50$ & $1.73 \pm 1.00$ & $1.31 \pm 0.49$ & $139.67 \pm 20.01$ & $85.98 \pm 11.29$ & $98.17 \pm 11.03$ \\
\hline & $65+$ & $5.75 \pm 1.51$ & $1.55 \pm 0.98$ & $1.30 \pm 0.50$ & $144.14 \pm 21.24$ & $83.35 \pm 11.49$ & $97.86 \pm 10.81$ \\
\hline & Total & $5.30 \pm 1.02$ & $1.09 \pm 0.88$ & $1.26 \pm 0.45$ & $130.04 \pm 16.65$ & $80.39 \pm 10.52$ & $91.11 \pm 10.48$ \\
\hline \multirow{8}{*}{ Female } & $10.00-17.99$ & $4.89 \pm 0.56$ & $1.09 \pm 0.64$ & $1.40 \pm 0.39$ & $108.15 \pm 13.43$ & $68.82 \pm 9.41$ & $70.40 \pm 9.47$ \\
\hline & $18.00-24.99$ & $4.83 \pm 0.71$ & $1.12 \pm 0.52$ & $1.49 \pm 0.45$ & $111.82 \pm 12.23$ & $72.32 \pm 8.85$ & $72.61 \pm 9.65$ \\
\hline & $25.00-34.99$ & $4.92 \pm 0.63$ & $1.16 \pm 0.63$ & $1.54 \pm 0.48$ & $113.99 \pm 13.54$ & $74.31 \pm 9.51$ & $75.78 \pm 10.51$ \\
\hline & $35.00-44.99$ & $5.08 \pm 0.73$ & $1.30 \pm 0.71$ & $1.54 \pm 0.59$ & $119.16 \pm 15.42$ & $77.60 \pm 10.31$ & $80.28 \pm 11.68$ \\
\hline & $45.00-54.99$ & $5.28 \pm 0.97$ & $1.50 \pm 0.80$ & $1.55 \pm 0.50$ & $127.44 \pm 18.15$ & $81.53 \pm 10.91$ & $85.85 \pm 12.41$ \\
\hline & $55.00-64.99$ & $5.48 \pm 1.27$ & $1.65 \pm 0.84$ & $1.54 \pm 0.58$ & $133.85 \pm 19.61$ & $82.93 \pm 11.09$ & $90.02 \pm 12.68$ \\
\hline & $65+$ & $5.69 \pm 1.47$ & $1.65 \pm 0.89$ & $1.51 \pm 0.52$ & $143.87 \pm 22.35$ & $83.08 \pm 11.76$ & $91.84 \pm 12.00$ \\
\hline & Total & $5.17 \pm 0.90$ & $1.35 \pm 0.72$ & $1.51 \pm 0.50$ & $122.61 \pm 16.39$ & $77.23 \pm 10.26$ & $80.97 \pm 11.20$ \\
\hline
\end{tabular}

Table 4. Age-adjusted prevalence (rate per 1,000) of metabolic syndrome, it's five components and 0-5 risk factors by sex and individual years

\begin{tabular}{|c|c|c|c|c|c|c|c|c|c|c|c|c|c|}
\hline & & MetS & $A O$ & TG & BP & Glu & HDL & $0 \mathrm{RF}$ & $1 \mathrm{RF}$ & $2 \mathrm{RF}$ & $3 \mathrm{RF}$ & $4 \mathrm{RF}$ & $5 \mathrm{RF}$ \\
\hline \multirow{10}{*}{ Male } & 2003 & 278.51 & 414.62 & 261.87 & 538.86 & 323.20 & 385.45 & 166.94 & 254.22 & 247.33 & 185.85 & 106.87 & 37.51 \\
\hline & 2004 & 258.41 & 420.31 & 261.63 & 550.50 & 197.64 & 343.27 & 198.13 & 265.18 & 238.97 & 181.30 & 96.43 & 19.99 \\
\hline & 2005 & 247.09 & 396.40 & 310.23 & 511.15 & 230.48 & 313.59 & 204.67 & 271.12 & 233.74 & 167.13 & 96.43 & 26.91 \\
\hline & 2006 & 275.09 & 445.71 & 296.03 & 568.84 & 290.53 & 267.68 & 176.16 & 275.60 & 227.67 & 179.73 & 106.33 & 34.50 \\
\hline & 2007 & 247.44 & 448.25 & 269.55 & 525.07 & 212.04 & 264.42 & 206.50 & 267.79 & 252.01 & 170.46 & 80.54 & 22.70 \\
\hline & 2008 & 279.14 & 461.86 & 309.54 & 581.77 & 258.43 & 275.12 & 152.32 & 275.73 & 255.49 & 188.88 & 105.07 & 22.52 \\
\hline & 2009 & 315.20 & 481.15 & 393.95 & 581.29 & 262.61 & 259.34 & 154.18 & 245.21 & 247.29 & 200.88 & 126.27 & 26.17 \\
\hline & 2010 & 288.39 & 451.76 & 355.14 & 613.93 & 214.16 & 292.84 & 156.32 & 248.90 & 253.14 & 210.71 & 107.07 & 22.45 \\
\hline & 2011 & 294.86 & 471.53 & 333.79 & 569.77 & 276.08 & 333.99 & 136.19 & 251.33 & 268.83 & 213.46 & 96.00 & 34.18 \\
\hline & 2012 & 303.43 & 493.61 & 319.21 & 564.09 & 265.13 & 286.97 & 164.82 & 251.74 & 241.90 & 207.87 & 101.52 & 32.16 \\
\hline \multirow{10}{*}{ Female } & 2003 & 286.87 & 491.37 & 205.92 & 412.51 & 283.18 & 371.16 & 225.14 & 260.71 & 209.85 & 167.69 & 102.41 & 33.86 \\
\hline & 2004 & 237.91 & 464.88 & 178.51 & 406.61 & 174.84 & 384.20 & 243.08 & 280.53 & 226.34 & 147.96 & 80.87 & 21.21 \\
\hline & 2005 & 251.40 & 486.58 & 244.89 & 389.89 & 198.89 & 342.44 & 228.37 & 281.15 & 224.53 & 154.86 & 89.23 & 21.85 \\
\hline & 2006 & 274.36 & 512.74 & 222,66 & 409.24 & 260.21 & 326.77 & 216.34 & 276.25 & 220.92 & 165.21 & 89.38 & 31.90 \\
\hline & 2007 & 234.37 & 520.23 & 200.82 & 410.84 & 175.52 & 278.56 & 253.62 & 265.00 & 237.11 & 151.86 & 72.80 & 19.60 \\
\hline & 2008 & 252.47 & 530.37 & 230.29 & 420.68 & 173.03 & 315.33 & 217.91 & 287.40 & 235.43 & 154.85 & 80.67 & 23.74 \\
\hline & 2009 & 296.58 & 538.82 & 289.98 & 435.76 & 226.60 & 293.40 & 219.18 & 246.93 & 224.97 & 180.51 & 96.01 & 32.24 \\
\hline & 2010 & 271.61 & 540.89 & 270.78 & 432.38 & 181.45 & 304.42 & 200.05 & 277.55 & 196.53 & 176.41 & 85.02 & 19.38 \\
\hline & 2011 & 279.42 & 535.84 & 271.48 & 414.06 & 231.75 & 315.42 & 208.32 & 260.24 & 239.01 & 171.04 & 92.21 & 29.18 \\
\hline & 2012 & 269.72 & 561.04 & 266.81 & 375.09 & 216.75 & 292.52 & 213.31 & 273.31 & 227.50 & 152.63 & 94.83 & 27.65 \\
\hline
\end{tabular}

MetS - metabolic syndrome; AO - abdominal obesity; TG - triglyceride; BP - blood pressure; Glu - glucose; HDL - HDL-cholesterol; RF - risk factor(s)

in males throughout the period exceeded that of females (males 197.64 to $323.2 / 1,000$, females from 173.03 to $283.18 / 1,000$ ). The prevalence of reduced HDL cholesterol decreased during the period (Fig. 8), the prevalence of reduced HDL cholesterol in females exceeded that one in males throughout the period (females
278.56 to $371.16 / 1,000$, males 259.34 to $385.45 / 1,000$ ), with the exception of the years 2003 and 2011 (Table 4).

From 2003 to 2012 the age-adjusted prevalence of zero and one risk determinants of MetS decreased (Table 4). More females were without risk factors (RF) (200.05 to $253.62 / 1,000)$ than males 
Table 5. The prevalence of metabolic syndrome by sex, age groups and individual years

\begin{tabular}{|c|c|c|c|c|c|c|c|c|c|c|c|}
\hline & & $\begin{array}{l}2003 \\
\text { n (\%) }\end{array}$ & $\begin{array}{l}2004 \\
\mathrm{n}(\%)\end{array}$ & $\begin{array}{l}2005 \\
\mathrm{n}(\%)\end{array}$ & $\begin{array}{l}2006 \\
\mathrm{n}(\%)\end{array}$ & $\begin{array}{l}2007 \\
\text { n (\%) }\end{array}$ & $\begin{array}{l}2008 \\
\text { n (\%) }\end{array}$ & $\begin{array}{l}2009 \\
\mathrm{n}(\%)\end{array}$ & $\begin{array}{l}2010 \\
\mathrm{n}(\%)\end{array}$ & $\begin{array}{l}2011 \\
\mathrm{n}(\%)\end{array}$ & $\begin{array}{l}2012 \\
\text { n (\%) }\end{array}$ \\
\hline \multirow{7}{*}{ Male } & $10.00-17.99$ & $1(2.3)$ & $2(4.0)$ & $4(4.4)$ & $1(3.2)$ & $0(0.0)$ & $1(2.0)$ & $2(2.4)$ & $1(1.5)$ & $1(2.8)$ & $2(5.4)$ \\
\hline & $18.00-24.99$ & $24(7.9)$ & $14(5.0)$ & $14(4.3)$ & $21(8.7)$ & $14(3.5)$ & $26(6.7)$ & $16(6.7)$ & $21(8.5)$ & $19(8.6)$ & $27(10.6)$ \\
\hline & $25.00-34.99$ & $87(16.8)$ & $78(14.9)$ & 90 (16.6) & $83(18.2)$ & $119(16.6)$ & $113(20.0)$ & $137(25.1)$ & $108(21.3)$ & $82(21.9)$ & $88(23.2)$ \\
\hline & $35.00-44.99$ & $153(24.9)$ & $147(27.2)$ & $121(23.7)$ & $139(29.8)$ & $187(25.9)$ & $164(29.9)$ & $204(35.7)$ & $145(31.4)$ & $115(32.2)$ & $124(28.8)$ \\
\hline & 4.99 & $9(41.1)$ & $225(36.59)$ & $241(35.0)$ & $225(37.2)$ & $328(36.8)$ & $284(41.8)$ & $250(42.6)$ & $168(35.8)$ & $143(40.4)$ & $172(44.0)$ \\
\hline & $55.00-64.99$ & $211(47.3)$ & $149(44.2)$ & $181(46.2)$ & $141(40.8)$ & $256(41.1)$ & $214(44.4)$ & $217(48.3)$ & $197(49.4)$ & $149(46.3)$ & $194(50.8)$ \\
\hline & $65+$ & $126(48.7)$ & $117(45.4)$ & $92(38.5)$ & $82(47.7)$ & $163(41.7)$ & $00(40.0)$ & $120(50.2)$ & $74(44.6)$ & 66 (44.3) & $58(39.7)$ \\
\hline \multirow{7}{*}{ Female } & $10.00-17.99$ & $1(1.3)$ & $1(0.9)$ & $4(3.9)$ & $2(7.1)$ & $0(0.0)$ & $4(5.1)$ & $3(4.3)$ & $3(3.7)$ & $1(3.6)$ & $2(2.7)$ \\
\hline & $18.00-24.99$ & $13(2.7)$ & $9(2.4)$ & $12(3.4)$ & $21(4.9)$ & $20(3.3)$ & $17(3.2)$ & $25(6.3)$ & $25(6.6)$ & $13(4.4)$ & $11(3.4)$ \\
\hline & $25.00-34.99$ & $78(7.2)$ & $46(5.2)$ & $80(9.0)$ & $54(6.6)$ & $98(7.2)$ & $78(7.5)$ & $103(10.4)$ & $98(11.2)$ & $63(11.2)$ & $46(8.8)$ \\
\hline & $35.00-44.99$ & $287(17.5)$ & $179(13.6)$ & 240 (19.7) & 215 (18.5) & $230(14.3)$ & $251(18.0)$ & $278(21.9)$ & $169(16.5)$ & $105(16.5)$ & $133(19.1)$ \\
\hline & $45.00-54.99$ & $797(39.0)$ & $461(29.3)$ & $505(32.2)$ & $510(33.5)$ & $649(29.9)$ & $580(32.9)$ & $534(33.6)$ & $383(32.3)$ & $304(35.8)$ & 260 (32.1) \\
\hline & $55.00-64.99$ & $451(51.0)$ & $327(47.5)$ & $285(42.4)$ & $333(48.3)$ & $495(41.5)$ & $380(42.8)$ & $467(48.2)$ & $355(46.8)$ & $283(46.9)$ & $317(48.9)$ \\
\hline & $65+$ & 331 (61.9) & $257(51.1)$ & $225(49.9)$ & $244(58.8)$ & $343(50.4)$ & $259(52.6)$ & $338(63.7)$ & $218(57.7)$ & $199(58.9)$ & $191(55.8)$ \\
\hline
\end{tabular}

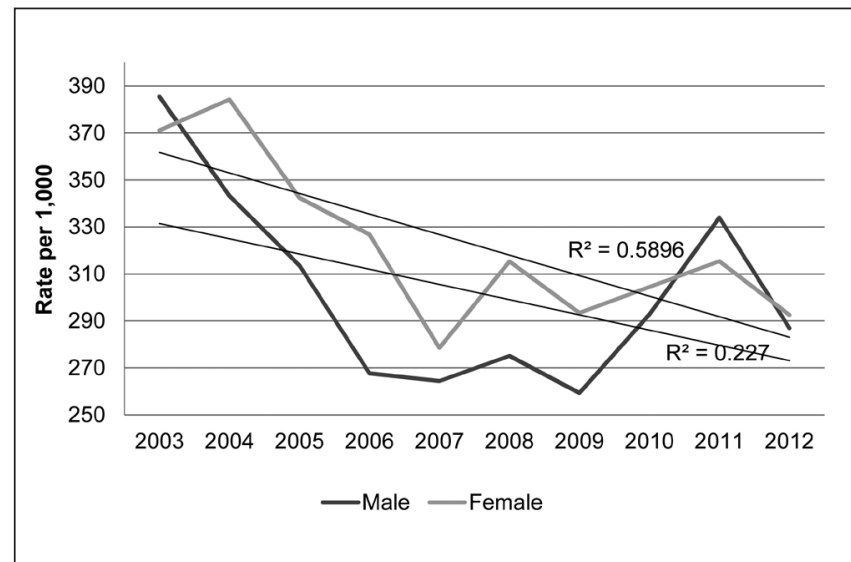

Fig. 8. Age-adjusted prevalence of impaired HDL cholesterol by sex and individual years.

(136.19 to $206.50 / 1,000)$. The same results were corresponding with one risk factor (females 246.93 to $287.40 / 1,000$, males 245.21 to $275.73 / 1,000)$, with the exception of the years 2006 and 2007 (Table 4). In respondents with two risk determinants of MetS, age-adjusted prevalence slightly increased during the time period, and all age groups were dominated by males (males 227.67 to $268.83 / 1,000$, females 196.53 to $239.01 / 1,000$ ). The age-adjusted prevalence of three risk factors in males has a time increasing trend, as well as the occurrence of four risk factors. In both categories each reference year was dominated by males (three risk factors from 167.13 to $213.46 / 1,000$, four risk factors from 80.54 to $126.27 / 1,000)$. The age-adjusted prevalence of three risk factors in females slightly increased and the prevalence of four risk factors stagnated (three risk factors from 147.96 to $180.51 / 1000$, four risk factors from 72.80 to $102.41 / 1,000$ ). The trend of prevalence of five risk factors in males stagnated, in females it slightly decreased. The values did not significantly differ between males and females (males from 19.99 to 37.51/1,000, females from 19.38 to $33.86 / 1,000$ ) (Table 4).
Table 5 shows the prevalence of MetS according to sex and age group in each year from 2003 to 2012. Both sexes and each year has a traceable increase in the proportion of people with MetS by age.

\section{DISCUSSION}

The observed overall prevalence of MetS, based on IDF criteria from 2006 (17), in monitored group in the Slovak Republic were $30.2 \%$ in males and $26.6 \%$ in females. Worldwide prevalence of MetS ranges from $<10 \%$ to as much as $84 \%$, depending on the definition of the syndrome used, the region, urban or rural environment, and composition of the population studied $(18,19)$. The prevalence of MetS, based on NCEP-ATP III criteria from 2001, varied from $8 \%$ to $43 \%$ in males and from $7 \%$ to $56 \%$ in females around the world (20). In general, the IDF estimates that one-quarter of the world's adult population has the MetS (17). Our results on the MetS syndrome occurrence essentially corresponds with the findings of authors of various surveys on the prevalence of MetS in Slovakia. In 2002, the project "MONIKA Slovak Republic" confirmed that in the 25-64-year-old population there was a $31 \%$ prevalence of MetS, in both men and women. The same prevalence of MetS in men from the same age group was found in the project "MONIKA Czech Republic", the prevalence in women was lower, $24.4 \%$ (21). In another Slovak survey carried out in 2005 in the age group from 18 years of age $38.1 \%$ prevalence of MetS was found (22). Project "NEMESYS" in a nationwide, cross-sectional, multicentre screening for MetS, demonstrated the prevalence of metabolic syndrome in $25.6 \%$ of outpatient clients (23).

The prevalence of MetS is highly age-dependent. In our survey, the prevalence of MetS in both genders has an increasing trend by age groups, and varied from $2.8 \%$ in the $10-17$ years age group to $52.0 \%$ in the more than 65 years of age group. Comparison by sex confirmed that the prevalence of MetS in females was lower than in males, with the most significant difference noticeable in 
the 25-34 age group, where the prevalence of MetS in males was more than double compared to females (males $19.2 \%$, females $8.2 \%$ ). Conversely, in the age group of more than 65 years, the prevalence of MetS in females significantly exceeded the prevalence of MetS in males. Park et al. (24) noticed that there is an increase in the prevalence of MetS from 20 years old through the sixth and seventh decade of life for males and females, respectively. The age-dependence of MetS is demonstrated in the Iranian population too, in which the prevalence is less than $10 \%$ for both men and women in the 20-29 age group, rising to $38 \%$ and $67 \%$ in the $60-69$ age group for men and women, respectively (25). Similarly, in the French population the prevalence rises from less than $5.6 \%$ in the $30-39$ age group to $17.5 \%$ in the 60-64 age group (26).

In our survey rather strict criterion for the assessment of abdominal obesity was chosen (according to the IDF definition - waist circumference $\geq 94 \mathrm{~cm}$ in males and $\geq 80 \mathrm{~cm}$ in females), thus there was a higher prevalence of abdominal obesity. The prevalence of abdominal obesity was higher among females $(53.9 \%)$ than in males $(48.3 \%)$, which is consistent with the findings of project "NEMESYS" which showed a prevalence of abdominal obesity of $65.9 \%$, with a significantly higher prevalence in females than in males: $72.6 \%$ vs. $56.6 \%(p<0.001)(23)$. The prevalence of raised triglyceride levels, BP and glucose was higher in males, while the prevalence of lower HDL cholesterol was slightly higher in females than in males.

\section{CONCLUSIONS}

During the reporting period from 2003-2012, the results of our large cross-sectional study confirmed unfavourable increasing trends in the age-adjusted prevalence of MetS among the clients of Health Advice Centres and simultaneous reduction in the number of persons without the presence of MetS risk determinants. Adverse finding during the whole period is the increased number of persons with abdominal obesity and elevated triglyceride levels in both sexes. A positive and surprising finding is the decrease in the proportion of clients with impaired levels of HDL-cholesterol. The proportion of people with elevated BP and glucose showed little change during the reported period compared to American figures from the National Health and Nutrition Examination Survey (NHANES) from 1999-2010, according to which the ageadjusted prevalence of MetS in the US decreased from $25.5 \%$ to $22.9 \%$, hypertriglyceridemia prevalence decreased from $33.5 \%$ to $24.3 \%$, as did elevated blood pressure from $32.3 \%$ to $24.0 \%$. This shows that our data about the clients of Health Advice Centres of Regional Public Health Authorities in Slovakia is alarming. A similar problem in the US as well as Slovakia is the increasing prevalence of elevated waist circumference $(45.4 \%$ to $56.1 \%)(27)$.

In our study the choice of clients was limited by bias (the selection of respondents was not random), therefore, the results cannot be applied to the whole population of Slovakia.

Our results demonstrate the need to address the increasing prevalence of MetS by targeting abdominal obesity and increased levels of triglycerides to reduce the future burden of CVD and T2DM, and confirm the urgent need for multi-faceted and coordinated treatment programmes as a healthcare priority.

\section{Acknowledgements}

We would like to thank the staff of the Health Advice Centres of Regional Public Health Authorities in the Slovak Republic for collaborating on this study.

\section{Conflict of Interests}

None declared

\section{REFERENCES}

1. World Health Organization. 2008-2013 Action plan for the global strategy for the prevention and control of noncommunicable diseases. Geneva: WHO; 2009.

2. Mortality from heart disease and stroke. In: OECD. Health at a glance 2011: OECD Indicators. OECD Publishing; 2011. p. 28-9.

3. Reaven GM. Role of insulin resistance in human disease. Diabetes. 1988 Dec;37(12):1595-607.

4. World Health Organization. Definition, diagnosis and classification of diabetes mellitus and its complications: report of a WHO consultation. Pt. 1, Diagnosis and classification of diabetes mellitus. Geneva: WHO; 1999.

5. Grundy SM, Brewer HB Jr, Cleeman JI, Smith SC Jr, Lenfant C. Definition of metabolic syndrome: Report of the National Heart, Lung, and Blood Institute/American Heart Association conference on scientific issues related to definition. Circulation. 2004;109(3):433-8.

6. Balkau B, Charles MA; European Group for the Study of Insulin Resistance (EGIR). Comment on the provisional report from the WHO consultation. Diabet Med. 1999 May;16(5):442-3.

7. Alberti KG, Zimmet P, Shaw J. The metabolic syndrome - a new worldwide definition. Lancet. 2005;366(9491):1059-62.

8. Alberti KG, Eckel RH, Grundy SM, Zimmet PZ, Cleeman JI, Donato $\mathrm{KA}$, et al.; International Diabetes Federation Task Force on Epidemiology and Prevention, National Heart, Lung, and Blood Institute, American Heart Association, World Heart Federation, International Atherosclerosis Society, International Association for the Study of Obesity. Harmonizing the metabolic syndrome: a joint interim statement of the International Diabetes Federation Task Force on Epidemiology and Prevention; National Heart, Lung, and Blood Institute; American Heart Association; World Heart Federation; International Atherosclerosis Society; and International Association for the Study of Obesity. Circulation. 2009 Oct 20;120(16):1640-5.

9. Kassi E, Pervanidou P, Kaltsas G, Chrousos G. Metabolic syndrome: definitions and controversies. BMC Med. 2011 May 5;9:48. doi: 10.1186/1741-7015-9-48.

10. Haffner SM, Valdez RA, Hazuda HP, Mitchell BD, Morales PA, Stern MP. Prospective analysis of the insulin-resistance syndrome (syndrome X). Diabetes. 1992;41(6):715-22

11. Isomaa B, Almgren P, Tuomi T, Forsén B, Lahti K, Nissén M, et al Cardiovascular morbidity and mortality associated with the metabolic syndrome. Diabetes Care. 2001 Apr;24(4):683-9.

12. Trevisan M, Liu J, Bahsas FB, Menotti A. Syndrome X and mortality: a population-based study. Am J Epidemiol.1998;148(10):958-66.

13. Ford ES, Giles WH, Dietz WH. Prevalence of the metabolic syndrome among US adults: findings from the Third National Health and Nutrition Examination Survey. JAMA. 2002;287(3):356-9.

14. Simmons RK, Alberti KG, Gale EA, Colagiuri S, Tuomilehto J, Qiao Q, et al. The metabolic syndrome: useful concept or clinical tool? Report of a WHO Expert Consultation. Diabetologia. 2010;53(4):600-60.

15. International Diabetes Federation. The IDF consensus definition of the metabolic syndrome in children and adolescents. Brussels: IDF; 2007.

16. Avdičová M. Methodological handbook for work in Health Advice Centres: a manual for Health Advice Centres of the National Institute of Public Health in Slovakia. Bratislava: Ministry of Health of the Slovak Republic; 2000. (In Slovak.)

17. International Diabetes Federation: The IDF consensus worldwide definition of the metabolic syndrome. Brussels: IDF; 2006.

18. Desroches S, Lamarche B. The evolving definitions and increasing prevalence of the metabolic syndrome. Appl Physiol Nutr Metab. 2007;32(1):23-32.

19. Kolovou GD, Anagnostopoulou KK, Salpea KD, Mikhailidis DP. The prevalence of metabolic syndrome in various populations. Am J Med Sci. 2007;333(6):362-71 
20. Cameron AJ, Shaw JE, Zimmet PZ. The metabolic syndrome: prevalence in worldwide populations. Endocrinol Metab Clin North Am. 2004;33(2):351-75

21. Nevrlka J, Souček M. Metabolic syndrome and hypertension. Remedia. 2006;16(2):146-51. (In Czech.)

22. Mokáň M, Galajda P, Prídavková D, Tomášková V, Šutarík L', Kručinská L, et al. Prevalence of diabetes mellitus and metabolic syndrome in Slovakia. Diabetes Obes. 2006;6(12):10-6. (In Slovak.)

23. Lietava J, Kosmálová V, Turek P, Šomlo P, Dukát A. Project NEMESYS: screening for metabolic syndrome in outpatients. Int Med. 2006;6(12):685-9. (In Slovak.)

24. Park YW, Zhu S, Palaniappan L, Heshka S, Carnethon MR, Heymsfield SB. The metabolic syndrome: prevalence and associated risk factor findings in the US population from the Third National Health and Nutrition Examination Survey, 1988-1994. Arch Intern Med. 2003;163(4):427-36.
25. Azizi F, Salehi P, Etemadi A, Zahedi-Asl S. Prevalence of metabolic syndrome in an urban population: Tehran Lipid and Glucose Study. Diab Res Clin Pract. 2003;61(1):29-37.

26. Balkau B, Vernay M, Mhamdi L, Novak M, Arondel D, Vol S, et al. The incidence and persistence of the NCEP (National Cholesterol Education Program) metabolic syndrome. The French D.E.S.I.R. study. Diabet Metab. 2003;29(5):526-32.

27. Beltrán-Sánchez H, Harhay MO, Harhay MM, Mcelligott S. Prevalence and trends of metabolic syndrome in the adult U.S. population, 19992010. J Am Coll Cardiol. 2013;62(8):697-703

Received October 27, 2016 Accepted in revised form April 24, 2017 